\title{
A Method for Transmission System Expansion Planning Considering Probabilistic Reliability Criteria
}

\author{
Jaeseok Choi, Senior Member, IEEE, Trungtinh Tran, A. (Rahim) A. El-Keib, Senior Member, IEEE, \\ Robert Thomas, Fellow, IEEE, HyungSeon Oh, and Roy Billinton, Fellow, IEEE
}

\begin{abstract}
This paper proposes a method for choosing the best transmission system expansion plan considering a probabilistic reliability criterion ( ${ }_{R} L$ OLE). The method minimizes the investment budget for constructing new transmission lines subject to probabilistic reliability criteria, which consider the uncertainties of transmission system elements. Two probabilistic reliability criteria are used as constraints. One is a transmission system reliability criterion $\left({ }_{R} \mathrm{LOLE}_{\mathrm{TS}}\right.$ ) constraint, and the other is a bus/nodal reliability criterion $\left({ }_{R}\right.$ LOLE $\left._{B u s}\right)$ constraint. The proposed method models the transmission system expansion problem as an integer programming problem. It solves for the optimal strategy using a probabilistic branch and bound method that utilizes a network flow approach and the maximum flow-minimum cut set theorem. Test results on an existing 21-bus system are included in the paper. They demonstrate the suitability of the proposed method for solving the transmission system expansion planning problem subject to practical future uncertainties.
\end{abstract}

Index Terms-Branch and bound, probabilistic reliability criteria, transmission system planning.

\section{INTRODUCTION}

T RANSMISSION system expansion planning with open access to the transmission system has become a hot issue in the electricity energy industry in recent years [1], [2]. Electric market access has moved the industry from conventional monopolistic electricity markets to competitive markets [3], [4]. In a competitive market, the price of the delivered energy and the quality of energy supply, including voltage quality and reliability of service, are the main factors for business success. A key factor in today's competitive environment is the orientation toward customer needs and willingness to pay for quality [4]. Transmission system expansion planning addresses the problem of broadening and strengthening an existing generation and transmission network to optimally

Manuscript received February 23, 2005. This work was supported by the Electrical Industry Research Center (EIRC) of the Ministry of Commerce, Industry, and Energy (MOCIE) of Korea. Paper no. TPWRS-00097-2005.

J. Choi and T. Tran are with the Department of Electrical Engineering, Gyeongsang National University, 660-701 Chinju, Korea (e-mail: jschoi@nongae.gsnu.ac.kr; tttinh73@ hotmail.com).

A. A. El-Keib is with the Department of Electrical Engineering, Petroleum Institute, 2533 Abu Dhabi, United Arab Emirates (e-mail: ael-keib@pi.ac.ae).

R. Thomas and H. Oh are with the Department of Electrical and Computer Engineering, Cornell University, Ithaca, NY 14853 USA (e-mail: rjt1@cornell.edu; hs01@ cornell.edu).

R. Billinton is with the Department of Electrical Engineering, University of Saskatchewan, Saskatoon, SK S7N 5A9, Canada (e-mail: roy_billinton@young.usask.ca).

Digital Object Identifier 10.1109/TPWRS.2005.852142 serve a growing electricity market while satisfying a set of economic and technical constraints [5], [6]. The problem is to minimize the cost subject to a reliability level constraint [7]. Various techniques, including branch and bound, sensitivity analysis, Bender decomposition, simulated annealing, genetic algorithms, tabu search, and greedy randomized adaptive search procedure (GRASP), have been used to study the problem [8]-[17]. It is difficult to obtain the optimal solution of a composite power system considering the generators and transmission lines simultaneously in an actual system, and therefore, transmission system expansion planning is usually performed after generation expansion planning. Deterministic reliability criteria such as a $\mathrm{N}-1$ or $\mathrm{N}-2$ contingency criteria and load balance constraints are used in most transmission system and composite power system expansion planning because of computation time problems. The recent blackouts that have occurred in countries worldwide call for strengthening the grid structure in order to establish successful deregulated electricity markets. The incidents call for the development of tools that can address uncertainties and significantly enhance the ability to conduct effective transmission planning [18]. Available transfer capability (ATC) is one good key parameter that indicates the ability of a power system to reliably increase the transferred power between two zones or two points. NERC suggests the transfer reliability criterion (TRC) based on the ATC for ISO operating and planning of a transmission system. The TRC is based on the $\mathrm{N}-1$ contingency deterministic criteria concept. It has been used effectively for transmission system planning in regulated environments. A probabilistic total transfer capability (TTC) methodology has been recently proposed [19].

Normally, the power system expansion planning problem is analyzed using a macro approach and then a micro approach considering the stability and dynamic characteristics of the new system. In a deregulated environment, electric utilities are expected to be winners in competition. Successful electricity market operation in such an environment depends on the transmission system and nodal (bus) reliability management [3]-[6]. Deregulated electricity markets, therefore, call for nodal-based indices in system operation and planning. Nodal reliability indices together with related information can be used for the management and control of congestion and reliability by ISO and TRANSCO in deregulated markets [3], [4]. This environment makes it important to assess and provide reasonable reliability criteria at the load points [4]. In such an environment, probabilistic reliability indices become important parameters 


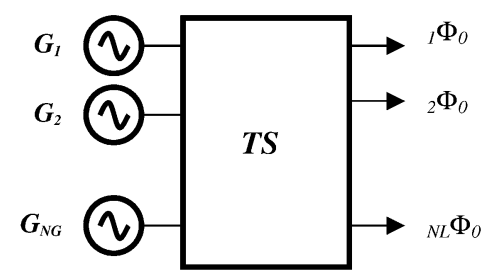

Fig. 1. Composite power system, including the transmission system.

in transmission system expansion. In addition, in a competitive electricity market, there is more variability in the investment budget for construction and higher uncertainty in the transfer reliability of the transmission system. This is because profit maximization for the system owner is the major focus, while, for a conventional power system, the primary function is to provide electrical energy to its customers economically and with an acceptable degree of continuity and quality. System planners and owners are, therefore, expected to evaluate the reliability and economic parameters with more detail in grid planning, where the problem involves many uncertainties, including those of the investment budget, reliability criterion, load forecast, and system characteristics[2]. It is a challenging task to develop an expansion plan that considers all these items in an effective and practical manner. Under such uncertain circumstances, methodologies that are based on fuzzy set theory and probabilistic approaches become attractive and useful to accomplish the task. The former is attractive because the experience and knowledge of experts and decision makers can be very helpful in dealing with subjective ambiguity in planning problems [20], [21]. The latter is also valuable for considering the objective uncertainties, such as the forced outage rates (FORs) of power system elements [22], [23].

This paper proposes a new method for choosing the best expansion plan for a transmission system considering a transmission system probabilistic reliability criterion $\left({ }_{R} \mathrm{LOLE}\right)$. Two probabilistic reliability criteria are used as constraints. One is a transmission system reliability criterion constraint required loss of load expectation of transmission system $\left({ }_{R} \mathrm{LOLE}_{\mathrm{TS}}\right)$, and the other is a bus/nodal reliability criterion constraint required loss of load expectation at bus/node $\left({ }_{R} \mathrm{LOLE}_{\mathrm{Bus}}\right)$. The proposed method minimizes the investment budget for constructing new transmission lines subject to probabilistic reliability criteria, which considers the uncertainties of transmission system elements. It models the transmission system expansion problem as an integer programming problem. It solves for the optimum mix of transmission network expansion using a probabilistic branch and bound method that utilizes a network flow approach and the maximum flow-minimum cut set theorem [24]-[27].

\section{TRAnsmission System EXPANSION Planning Problem}

A composite power system that includes generation and transmission facilities is shown in Fig. 1. TS refers to the transmission system, NG is the number of generators, ${ }_{k} \Phi_{0}$ is the inverted load duration curve at load point $k$, and NL is the number of load points. In this paper, a composite power system is designated as Hierarchical level II (HLII), and Hierarchical level I (HLI) is

used to designate generation and load components only [28]. It is assumed that the generation system and transmission system plans are separated, and the construction of new generators is determined independently by GENCOs.

\section{A. Objective Function}

The conventional transmission system expansion planning problem is to minimize the total construction cost $C^{T}$ associated with investing in new transmission lines as expressed in [25]-[27]

$$
\operatorname{minimize} C^{T}=\sum_{(x, y) \in \rho}\left[\sum_{i=1}^{m(x, y)} C_{(x, y)}^{(i)} U_{(x, y)}^{(i)}\right]
$$

where

$\rho \quad$ set of all branches (transmission lines);

$m(x, y)$ number of new candidate branches connecting nodes $x$ and $y$;

$C_{(x, y)}^{(i)} \quad$ sum of the construction costs of the new lines $1 \mathrm{st}$ through $i$ th that connect buses $x$ and $y$

with

$$
C_{(x, y)}^{(i)}=\sum_{j=1}^{i} \Delta C_{(x, y)}^{(j)}
$$

$\Delta C_{(x, y)}^{(j)}$

nodes $x$ and $y$;

$U_{(x, y)}^{(i)} \quad$ decision variable associated with the line (1 if from 1 st to $i$ th lines are to be constructed, and 0 otherwise)

with $\sum_{i=1}^{m(x, y)} U_{(x, y)}^{(i)}=1$

$$
\begin{aligned}
& U_{(x, y)}^{(i)}=\left[\begin{array}{ll}
1 & P_{(x, y)}=P_{(x, y)}^{(0)}+P_{(x, y)}^{(i)} \\
0 & P_{(x, y)} \neq P_{(x, y)}^{(0)}+P_{(x, y)}^{(i)}
\end{array}\right. \\
& P_{(x, y)}^{(i)}=\sum_{j=1}^{i} \Delta P_{(x, y)}^{(j)}
\end{aligned}
$$

with

$P_{(x, y)}^{(i)}$

$\Delta P_{(x, y)}^{(j)}$

$P_{(x, y)}^{(0)}$ sum of the capacities of new branches (new transmission lines) between nodes $x$ and $y$;

capacity of the $j$ th element of the candidate branches connecting nodes $x$ and $y$;

capacity of the existing lines that connect nodes $x$ and $y$.

\section{B. Constraints}

The basic reliability criteria normally considered in a composite power system planning problem can be categorized as two types of constraints. One is a deterministic reliability criterion, and the other is the probabilistic reliability criterion.

In a deterministic approach, no shortage of power supply requires that the total capacity of the branches involved in the minimum cut set should be greater than or equal to the system peak load demand $L_{p}$. This is also referred to as the bottleneck capacity. Therefore, a no-shortage power supply constraint can be expressed by

$$
P_{C}(X, \bar{X}) \geq L_{p}(\mathrm{~s} \in X, \mathrm{t} \in \bar{X})
$$

where $P_{C}(X, \bar{X})$ is the capacity of the minimum cut set of two subsets $X$ and $\bar{X}$, containing source nodes $s$ and terminal nodes 
$t$, respectively, when all nodes are separated by a minimum cut set.

The demand constraint (3) can be expressed by (4) with $k$ being the cut set number $(k=1, \ldots, n)$, where $n$ is number of cut set

$$
\sum_{(x, y) \in\left(X_{k}, \bar{X}_{k}\right)}\left[P_{(x, y)}=P_{(x, y)}^{(0)}+\sum_{i=1}^{m(x, y)} P_{(x, y)}^{(i)} U_{(x, y)}^{(i)}\right] \geq L_{p} .
$$

In the probabilistic approach, the probabilistic reliability criterion index LOLE can be used as in

$$
\operatorname{LOLE}_{\mathrm{TS}}\left(P_{(x, y)}^{(i)}, \Phi\right) \leq_{R} \operatorname{LOLE}
$$

where ${ }_{R}$ LOLE is the required transmission reliability criterion for the new system. The ${ }_{R}$ LOLE is ${ }_{R} \mathrm{LOLE}_{\mathrm{TS}}$ for the transmission system reliability criterion case, and it is ${ }_{R} L^{2} \mathrm{LEE}_{\mathrm{Bus}}$ for the bus/nodal reliability criterion case. $\Phi$ is a function of the load duration curve. A detailed discussion of $\Phi$ and LOLE is presented in Section III.

\section{COMPosite POWER System Reliability EVALUATION}

The following is a brief introduction to the methodology used to determine the transmission system reliability indices and the bus/nodal reliability indices. The methodology is based on the composite power system effective load model developed by the authors in [31].

\section{A. Reliability Evaluation at HLI}

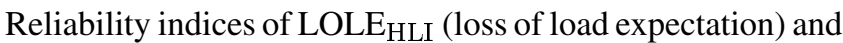
EENS $_{\mathrm{HLI}}$ (expected energy not served) at HLI considering only the generation system are calculated using the effective load duration curve (ELDC), $\mathrm{HLI} \Phi(x)$ of HLI as in (6) and (7), respectively

$$
\begin{aligned}
& \operatorname{LOLE}_{\mathrm{HLI}}=\left.{ }_{\mathrm{HLI}} \Phi(x)\right|_{x=\mathrm{IC}} \quad[\text { hours } / \mathrm{yr}] \\
& \mathrm{EENS}_{\mathrm{HLI}}=\int_{\mathrm{IC}}^{\mathrm{IC}+\mathrm{Lp}} \mathrm{HLI} \Phi(x) d x \quad[\mathrm{MWh} / \mathrm{yr}]
\end{aligned}
$$

where $I C$ is the total installed generating capacity [MW], $L_{p}$ is the system peak load [MW], and

$$
\begin{aligned}
\mathrm{HLI}_{i} \Phi_{i}\left(x_{e}\right) & ={ }_{\mathrm{HLI}} \Phi_{i-1}\left(x_{e}\right) \otimes_{\mathrm{HLI}} f_{o i}\left(x_{o i}\right) \\
& =\int_{\mathrm{HLI}} \Phi_{i-1}\left(x_{e}-x_{o i}\right)_{\mathrm{HLI}} f_{o i}\left(x_{o i}\right) d x
\end{aligned}
$$

where

$\otimes$

$$
{ }_{\mathrm{HLI}} \Phi_{0}\left(x_{e}-x_{o i}\right)=
$$
HLI $f_{o i}\left(x_{o i}\right)$ operator meaning convolution integral;

\section{$\operatorname{HLI} \Phi\left(x_{L}\right)$;}

probability distribution function of outage capacity of generator $\# i$.

\section{B. Reliability Evaluation at HL II (Composite Power System)}

The reliability indices at HLII can be classified as load point indices and bulk system indices, depending on the object of the evaluation. The reliability indices can be evaluated using a composite power system equivalent load duration curve (CMELDC)

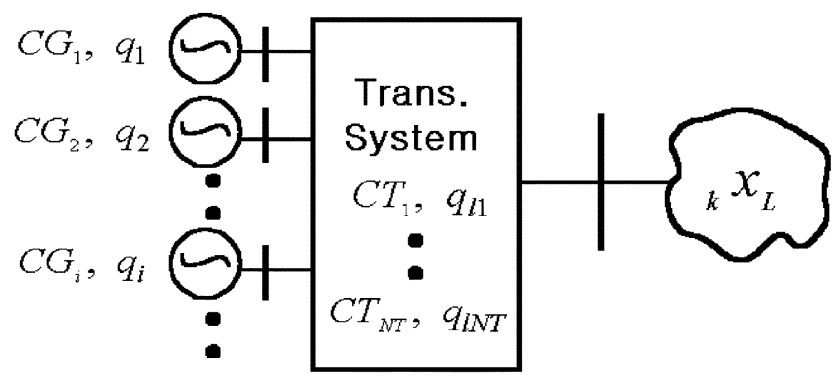

(a)

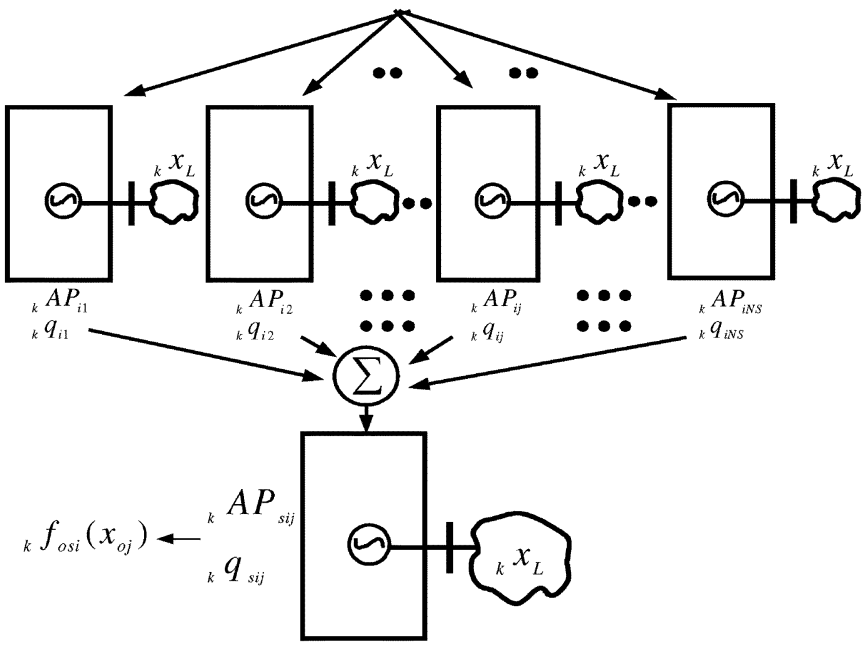

(b)

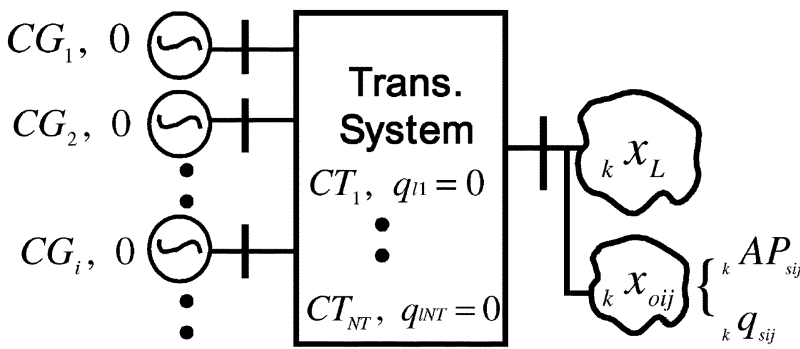

(c)

Fig. 2. Composite power system effective load model at HLII. (a) Actual system. (b) Synthesized fictitious equivalent generator. (c) Equivalent system.

of HLII based on the composite power system effective load model in Fig. 2 [29]-[31]. CG, CT, and $q$ and $q_{l}$ in Fig. 2 are the capacities and forced outage rates of the generators and transmission lines, respectively.

1) Reliability Indices at the Load Points (Buses): The load point reliability indices $\mathrm{LOLE}_{k}$ and EENS ${ }_{k}$ can be calculated using (9) and (10) with the CMELDC ${ }_{k} \Phi_{\mathrm{NG}}(x)$

$$
\begin{aligned}
& \operatorname{LOLE}_{k}=\left.{ }_{k} \Phi_{\mathrm{NG}}(x)\right|_{x=\mathrm{AP}_{k}} \quad \text { [hours/yr] } \\
& \mathrm{EENS}_{k}=\int_{\mathrm{AP}_{k}}^{\mathrm{AP}_{k}+L p_{k}}{ }_{k} \Phi_{\mathrm{NG}}(x) d x \quad[\mathrm{MWh} / \mathrm{yr}]
\end{aligned}
$$

where

$L_{\mathrm{pk}} \quad$ peak load at load point $k[\mathrm{MW}]$;

$\mathrm{AP}_{k}$ maximum arrival power at load point $k$ [MW]

$$
\begin{aligned}
{ }_{k} \Phi_{i}\left(x_{e}\right) & ={ }_{k} \Phi_{o}\left(x_{e}\right) \otimes_{k} f_{o s i}\left(x_{o i}\right) \\
& =\int{ }_{k} \Phi_{o}\left(x_{e}-x_{o i}\right){ }_{k} f_{o s i}\left(x_{o i}\right) d x_{o i}
\end{aligned}
$$


with

$\otimes \quad$ operator representing the convolution integral;

${ }_{k} \Phi_{0}=\quad$ original load duration curve at load point \#k;

${ }_{k} f_{o s i} \quad$ outage capacity $p d f$ of the synthesized fictitious gen-

erator created by generators 1 to $i$, at load point $\# k$.

2) Reliability Indices of the Bulk System: While the EENS $_{\text {HLII }}$ of a bulk system is equal to the summation of the EENS $_{k}$ at the load points as shown in (12), the LOLE of a bulk system is entirely different from the summation of the $\mathrm{LOLE}_{k}$ at the load points. The expected load curtailed ( $\left.\mathrm{ELC}_{\mathrm{HLII}}\right)$ of bulk system is equal to the summation of $\mathrm{ELC}_{k}$ at the load points. The LOLE using (14)

$$
\begin{aligned}
& \mathrm{EENS}_{\mathrm{HLII}}=\sum_{k=1}^{\mathrm{NL}} \mathrm{EENS}_{k} \quad[\mathrm{MWh} / \mathrm{yr}] \\
& \mathrm{ELC}_{\mathrm{HLII}}=\sum_{k=1}^{\mathrm{NL}} \mathrm{ELC}_{k} \quad[\mathrm{MW} / \mathrm{cur} \cdot \mathrm{yr}] \\
& \left.\mathrm{LOLE}_{\mathrm{HLII}}=\mathrm{EENS}_{\mathrm{HLII}} / \mathrm{ELC}_{\mathrm{HLII}} \quad \text { hours } / \mathrm{yr}\right] \\
& \mathrm{EIR}_{k}=1-\mathrm{EENS}_{k} / \mathrm{DENG}_{k} \quad \text { [p.u.] }
\end{aligned}
$$

where

NL number of load points;

$\mathrm{ELC}_{k} \quad \mathrm{EENS}_{k} / \mathrm{LOLE}_{k}$;

$\mathrm{DENG}_{k} \quad$ demand energy at bus $\#_{k}$.

\section{Reliability Evaluation of Transmission System}

The reliability indices of a transmission system can be expressed as the difference between the HLII and HLI reliability indices as shown in

$$
\begin{array}{ll}
\mathrm{EENS}_{\mathrm{TS}}=\mathrm{EENS}_{\mathrm{HLII}}-\mathrm{EENS}_{\mathrm{HLI}} & {[\mathrm{MWh} / \mathrm{yr}]} \\
\mathrm{LOLE}_{\mathrm{TS}} & =\mathrm{LOLE}_{\mathrm{HLII}}-\mathrm{LOLE}_{\mathrm{HLI}} \quad[\mathrm{hrs} / \mathrm{yr}] .
\end{array}
$$

\section{SOLUTION ALGORITHM}

The objective in the conventional branch and bound method is to minimize the total construction cost subject to a specified reliability criterion. The proposed probabilistic branch and boundbased method minimizes the total cost subject to the required probabilistic transmission system reliability criteria ${ }_{R} \mathrm{LOLE}_{\mathrm{TS}}$ and/or ${ }_{R}$ LOLE $_{\text {Bus }}$.

The solution algorithm for the proposed approach follows.

1) Check the need for transmission expansion for the system and its possibility using the candidate lines. Need and possibility can be checked, respectively, by the reliability evaluation for systems considering no candidate lines and considering all candidate lines.

2) Set $j=1$ (initial system), jopt $=0, j \max =$ $0, C^{T}$ opt $=\infty$, and $\mathrm{ENNOD}_{j}=0$.

3) If $\mathrm{ENNOD}_{j}=1$, the $\# j$ system is an end node at which the branch operation of a branch and bound is finished (bound) in the solution graph used to obtain the optimal solution, and there is no need to consider any of the other graphs following this system. Go to step 13).
4) Calculate the minimum cut set using the maximum flow method for system $j$ (solution $j$ in the solution graph).

5) Select a \#i branch/line of the candidate branches/lines set $\left(S_{j}\right)$ involved in the minimum cut set and add to the $\# j$ system. In what follows, the new system is named the system $j i$.

6) If the system $j i$ is already considered in the solution graph, go to step 13).

7) Calculate the total cost $C_{j i}^{T}=C_{j}^{T}+C\left(P_{(x, y)}^{(i)}\right)$ for the system $j i$ and evaluate the transmission system reliability index $\mathrm{LOLE}_{\mathrm{TS} j i}$ of the system.

8) If $C_{j i}^{T}<C_{\text {jopt }}^{T}$, the current system $(j i)$ with a cost of $C_{j i}^{T}$ can be optimal. If not, go to step 11).

9) $\quad$ Set $j \max =j \max +1$.

10) If $\mathrm{LOLE}_{\mathrm{TS} j i}$ (or $\left.\mathrm{LOLE}_{\mathrm{Bus} j i}\right)<_{R} \mathrm{LOLE}_{\mathrm{TS}}$, set $C_{\mathrm{opt}}^{T}=$ $C_{j i}^{T}$, and ${ }_{R} \mathrm{LOLE}_{\text {opt }}=\mathrm{LOLE}_{j i}$,jopt $=j \max$, and go to step 12).

11) Set $C_{j \max }^{T}=C_{j i}^{T}, \mathrm{ENNOD}_{j \max }=1$, and go to step $13)$.

12) Add the solution $j \max (j i)$ to the solution graph.

13) If all the candidate branches/lines in the cut set $S_{j}$ have been considered, go to step 14). Otherwise, set $i=i+1$ and go to step 5).

14) If $j=j \max$, continue to the next step. Otherwise, set $j=j+1$ and go to step 4).

15) For $j=j \max$, the solution graph has been constructed fully and the optimal solution jopt with $C^{T}{ }_{j \text { opt }}$ being the lowest cost and satisfies the required reliability criteria is obtained in step 10).

\section{CASE Study}

The proposed method was tested on the 21-bus model system shown in Fig. 3. This is a part of the southeast area (Youngnam) in Korea. Considering a future forecast system load, the deterministic reliability criterion and the proposed probabilistic reliability approaches were applied and compared in a series of case studies [32], [33]. The probabilistic approach considers the probabilistic reliability criterion without the deterministic constraints (demand balance).

Table I shows the system data with GN, TF, TL, and LD representing generators, transformers, transmission lines, and loads, respectively. SB and EB are start and end buses of the line, respectively. $\Delta P_{(x, y)}^{(0)}$ and $\Delta C_{(x, y)}^{(0)}$ are, respectively, the capacities and costs of existing lines that connect nodes $x$ and $y$. In this study, four candidate generators and lines are considered as it is, meaning that $m(x, y)=4$ in (1) and (4). In Table I, parentheses in $\Delta P_{(x, y)}^{(j)}$ and $\Delta C_{(x, y)}^{(j)}$ are omitted for convenience. The cost unit $\mathrm{M} \$$ in this table stands for millions of dollars. Table II shows the forced outage rate of the generators and transmission lines. Fig. 4 shows the inverted load duration curves at the buses with the four largest loads.

In the first case study, the required probabilistic transmission system reliability criterion ${ }_{R} \mathrm{LOLE}_{\mathrm{TS}}=50[\mathrm{hrs} / \mathrm{yr}]$ is assumed for base case. The new optimal system is shown in Fig. 5, with dotted lines presenting new lines. An optimal system that has the construction cost of $209[\mathrm{M} \$]$ and the new construction elements 


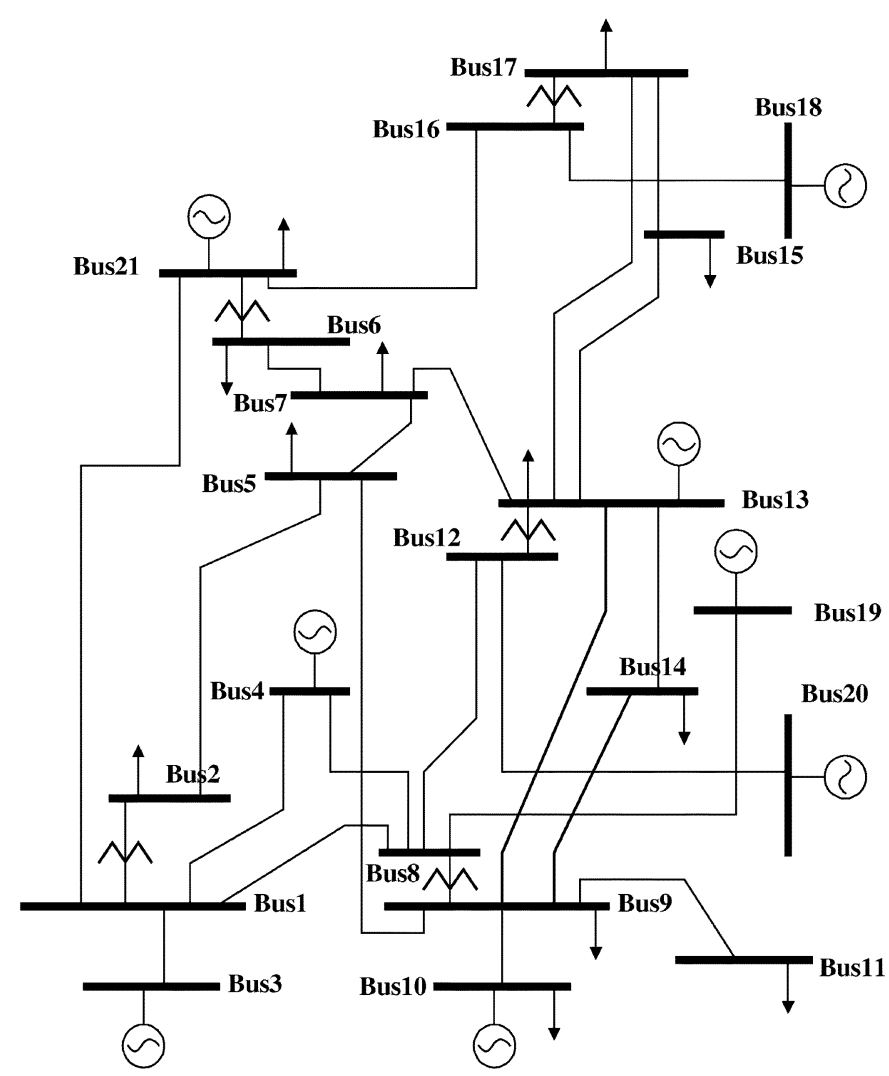

Fig. 3. 21-bus model system.

of $\mathrm{T}_{9-10}^{1}, \mathrm{~T}_{9-11}^{1}$ and $\mathrm{T}_{13-15}^{1}$ are obtained as the optimal solution of probabilistic approach proposed in this paper. The actual reliability level LOLE $\mathrm{TS}_{\mathrm{S}}$ of the optimal system was evaluated as 45.47 [hrs/yr], and this level is satisfied with a required probabilistic reliability criterion level(constraint) ${ }_{R} \mathrm{LOLE}_{\mathrm{TS}}=50$ [hrs/yr]. It is interesting to note that this system is the same as that produced using the deterministic approach with a bus reserve rate at $k$ load point $\mathrm{BBR}_{k}=0 \%$ for all load points [33]. $\mathrm{AP}_{k}$ and $L p_{k}$ are the maximum arrival power and peak load, respectively, at the $k$ load point. A deterministic bus/nodal reliability criterion, $\mathrm{BBR}_{k}$ is defined in [34] as

$$
\mathrm{BBR}_{k}=\left(\mathrm{AP}_{k}-L p_{k}\right) \times 100 / L p_{k} .
$$

Table III shows the reliability indices at the load buses in the case of ${ }_{R} \mathrm{LOLE}_{\mathrm{TS}}=50$ [hrs/yr]. This table shows that the nodal reliability indices can have different values from the transmission system reliability level LOLE $\mathrm{TS}=45.67$ [hrs/yr]. However, this table shows that the LOLE indices values at buses \#2, $\# 13$, and \#17 exceed the system reliability criteria $\left({ }_{R} \mathrm{LOLE}_{\mathrm{TS}}=\right.$ 50 [hrs/yr]).

Fig. 6 shows another new optimal system using the probabilistic approach with a ${ }_{R} \mathrm{LOLE}_{\mathrm{TS}}=25[\mathrm{hrs} / \mathrm{yr}]$ for the reliability criterion. This case utilizes a more severe reliability criterion than previous plans. The optimal solution has a construction cost of $511[\mathrm{M} \$]$ and the new construction elements of $\mathrm{TF}_{1-2}^{1}, \mathrm{~T}_{5-9}^{1}, \mathrm{~T}_{13-17}^{1}, \mathrm{~T}_{13-15}^{1}, \mathrm{~T}_{9-10}^{1}$, and $\mathrm{T}_{9-11}^{1}$. The evaluated reliability level LOLE $\mathrm{TS}_{\mathrm{T}}$ of the optimal system is 24.42 [hrs/yr], and this level satisfies the required probabilistic reliability criterion ${ }_{R} \mathrm{LOLE}_{\mathrm{TS}}=25$ [hrs/yr]. The new plan suggests a strong grid system with a high cost.
TABLE I

SySTEM CAPACITY AND COST DATA P(*): (MW) AND C $(*)$ : $(\mathrm{M} \$$ ) (\#0 and \#6 REPRESENT SOURCE AND TERMINAL NODES, RESPECTIVELY

\begin{tabular}{|c|c|c|c|c|c|c|c|c|c|c|c|c|c|}
\hline $\mathrm{NL}$ & $\mathrm{SB}$ & EB & ID & $\Delta P_{y}^{0}$ & $\Delta P_{y y}^{1}$ & $\Delta P_{x y}^{2}$ & $\Delta P_{x y}^{3}$ & $\Delta P_{x y}^{4}$ & $\Delta C_{x y}^{0}$ & $\Delta C_{x y}^{1}$ & $\Delta C_{x y}^{2}$ & $\Delta C_{x y}^{3}$ & $\Delta C_{x}^{4}$ \\
\hline 1 & 0 & 3 & GN & 850 & 0 & 0 & 0 & 0 & 0 & 0 & 0 & 0 & 0 \\
\hline 2 & 0 & 21 & GN & 900 & 0 & 0 & 0 & 0 & 0 & 0 & 0 & 0 & 0 \\
\hline 3 & 0 & 4 & GN & 850 & 0 & 0 & 0 & 0 & 0 & 0 & 0 & 0 & 0 \\
\hline 4 & & & $\mathrm{GN}$ & 900 & 0 & 0 & 0 & 0 & 0 & 0 & 0 & 0 & 0 \\
\hline 5 & $\begin{array}{l}0 \\
\end{array}$ & \begin{tabular}{|l|}
20 \\
\end{tabular} & \begin{tabular}{l|l}
$\mathrm{GN}$ \\
\end{tabular} & 1200 & 0 & 0 & 0 & 0 & 0 & 0 & 0 & 0 & 0 \\
\hline 6 & 0 & \begin{tabular}{|l|}
18 \\
\end{tabular} & GN & 850 & 0 & 0 & 0 & 0 & 0 & 0 & 0 & 0 & 0 \\
\hline 7 & 0 & \begin{tabular}{|l|}
13 \\
\end{tabular} & $\begin{array}{ll}\mathrm{GN} \\
\end{array}$ & 760 & 0 & 0 & 0 & 0 & 0 & 0 & 0 & 0 & 0 \\
\hline 8 & & \begin{tabular}{|l|}
19 \\
\end{tabular} & GN & 950 & 0 & 0 & 0 & 0 & & 0 & 0 & 0 & 0 \\
\hline 9 & 6 & \begin{tabular}{|l|}
21 \\
\end{tabular} & \begin{tabular}{l|l|}
$\mathrm{TF}$ \\
\end{tabular} & 1020 & 510 & 510 & 0 & 0 & 0 & $\begin{array}{l}132 \\
\end{array}$ & 132 & 0 & 0 \\
\hline 10 & 16 & \begin{tabular}{|l|}
17 \\
\end{tabular} & TF & 1020 & 510 & 510 & 0 & 0 & 0 & \begin{tabular}{|l|l}
124 \\
\end{tabular} & 124 & 0 & 0 \\
\hline 11 & 12 & \begin{tabular}{|l|}
13 \\
\end{tabular} & \begin{tabular}{l|l|}
$\mathrm{TF}$ \\
\end{tabular} & 1020 & 510 & 510 & 0 & 0 & 0 & \begin{tabular}{|l|}
123 \\
\end{tabular} & 130 & 0 & 0 \\
\hline 12 & 8 & \begin{tabular}{|l|}
9 \\
\end{tabular} & TF & 800 & \begin{tabular}{|l|l|}
800 \\
\end{tabular} & 0 & 0 & 0 & 0 & \begin{tabular}{|l|}
155 \\
\end{tabular} & 0 & 0 & 0 \\
\hline 13 & 1 & 2 & TF & 800 & 800 & 0 & 0 & 0 & 0 & \begin{tabular}{|l|}
151 \\
\end{tabular} & 0 & 0 & 0 \\
\hline 14 & 21 & 1 & $\mathrm{TL}$ & 500 & \begin{tabular}{|l|l|}
500 \\
\end{tabular} & 500 & 0 & 0 & 0 & 29 & 29 & 0 & 0 \\
\hline \begin{tabular}{ll|}
15 \\
\end{tabular} & 2 & 5 & \begin{tabular}{ll|}
$\mathrm{TL}$ \\
\end{tabular} & 220 & 2220 & 0 & 0 & 0 & 0 & 54 & 0 & 0 & 0 \\
\hline 16 & 1 & 4 & $\mathrm{TL}$ & 300 & 300 & 0 & 0 & 0 & 0 & 73 & 0 & 0 & 0 \\
\hline 17 & 1 & 8 & $\begin{array}{ll}\mathrm{TL} \\
\end{array}$ & 400 & 400 & \begin{tabular}{|l|}
0 \\
\end{tabular} & 0 & 0 & 0 & 70 & 0 & 0 & 0 \\
\hline 18 & 1 & 3 & TL & 1000 & 250 & 250 & 250 & 250 & 0 & 20 & 20 & 20 & 20 \\
\hline 19 & 4 & 8 & \begin{tabular}{ll|}
$\mathrm{TL}$ \\
\end{tabular} & 300 & 300 & \begin{tabular}{|c|}
0 \\
\end{tabular} & 0 & \begin{tabular}{|l|}
0 \\
\end{tabular} & 0 & 63 & 0 & 0 & 0 \\
\hline 20 & 5 & 9 & $\mathrm{TL}$ & 220 & 222 & 0 & 0 & 0 & 0 & 82 & 0 & 0 & 0 \\
\hline 21 & $\frac{5}{5}$ & & $\mathrm{TL}$ & 220 & \begin{tabular}{|l|l|}
220 \\
\end{tabular} & 0 & 0 & 0 & 0 & $\frac{72}{77}$ & 0 & 0 & 0 \\
\hline 22 & 7 & \begin{tabular}{|l|}
6 \\
\end{tabular} & $\mathrm{TL}$ & 220 & \begin{tabular}{|l|}
220 \\
\end{tabular} & 0 & 0 & 0 & 0 & 85 & 0 & 0 & 0 \\
\hline 23 & 21 & \begin{tabular}{|l|}
16 \\
\end{tabular} & TL & 1000 & 250 & 250 & \begin{tabular}{|l|l|}
250 \\
\end{tabular} & 250 & 0 & 30 & 30 & 30 & 30 \\
\hline 24 & & 13 & $\mathrm{TL}$ & 220 & 222 & 0 & 0 & 0 & 0 & 88 & 0 & 0 & 0 \\
\hline 25 & $\frac{1}{13}$ & \begin{tabular}{|l|}
17 \\
\end{tabular} & $\mathrm{TL}$ & 220 & \begin{tabular}{|l|l|}
220 \\
\end{tabular} & 0 & 0 & 0 & 0 & 69 & 0 & 0 & 0 \\
\hline 26 & 13 & \begin{tabular}{|l|}
15 \\
\end{tabular} & $\mathrm{TL}$ & 220 & 2220 & 0 & 0 & 0 & 0 & 83 & 0 & 0 & 0 \\
\hline 27 & 16 & \begin{tabular}{|l|}
18 \\
\end{tabular} & $\mathrm{TL}^{\mathrm{TL}}$ & 1320 & 330 & \begin{tabular}{|l|}
330 \\
\end{tabular} & 330 & 330 & 0 & 32 & 32 & 32 & 32 \\
\hline & & \begin{tabular}{|l|}
13 \\
\end{tabular} & $\mathrm{TL}$ & 220 & 222 & 0 & 0 & 0 & 0 & 71 & 0 & 0 & 0 \\
\hline 29 & 9 & \begin{tabular}{|l|}
14 \\
\end{tabular} & $\mathrm{TL}$ & 220 & \begin{tabular}{|l|l|}
220 \\
\end{tabular} & 0 & 0 & 0 & 0 & 65 & 0 & 0 & 0 \\
\hline 30 & 8 & \begin{tabular}{|l|}
19 \\
\end{tabular} & $\mathrm{TL}$ & 620 & \begin{tabular}{|l|l|}
620 \\
\end{tabular} & 0 & 0 & 0 & 0 & 64 & 0 & 0 & 0 \\
\hline 31 & 12 & \begin{tabular}{|l|}
20 \\
\end{tabular} & 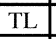 & 1240 & 310 & 310 & 310 & 310 & 0 & 28 & 28 & 28 & 28 \\
\hline & & & $\mathrm{TL}$ & 400 & 400 & 0 & 0 & 0 & 0 & 62 & 0 & 0 & 0 \\
\hline 33 & $\frac{12}{9}$ & \begin{tabular}{|l|}
10 \\
\end{tabular} & $\mathrm{TL}$ & 240 & \begin{tabular}{|l|l|}
240 \\
\end{tabular} & 0 & 0 & 0 & 0 & 81 & 0 & 0 & 0 \\
\hline 34 & 9 & \begin{tabular}{|l|l|}
11 \\
\end{tabular} & $\mathrm{TL}$ & 340 & \begin{tabular}{|l|l|}
340 \\
\end{tabular} & 0 & 0 & 0 & 0 & 45 & 0 & 0 & 0 \\
\hline 35 & 15 & \begin{tabular}{|l|}
17 \\
\end{tabular} & \begin{tabular}{ll|}
$\mathrm{TL}$ \\
\end{tabular} & 220 & 2220 & 0 & 0 & 0 & 0 & 80 & 0 & 0 & 0 \\
\hline & & & $\mathrm{TL}$ & 220 & 220 & & & 0 & 0 & 80 & 0 & 0 & 0 \\
\hline$\frac{1}{30}$ & 21 & \begin{tabular}{|l|}
22 \\
2
\end{tabular} & $\mathrm{LD}$ & 785 & \begin{tabular}{|c|}
20 \\
\end{tabular} & 0 & 0 & 0 & 0 & 0 & 0 & 0 & 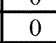 \\
\hline & 6 & \begin{tabular}{|l|}
22 \\
\end{tabular} & LD & 750 & 0 & 0 & 0 & 0 & 0 & 0 & 0 & 0 & 0 \\
\hline & 2 & \begin{tabular}{|l|}
22 \\
\end{tabular} & LD & 850 & 0 & 0 & 0 & 0 & 0 & 0 & 0 & 0 & 0 \\
\hline 40 & 9 & \begin{tabular}{|l|}
22 \\
\end{tabular} & LD & 595 & 0 & 0 & 0 & 0 & 0 & 0 & 0 & 0 & 0 \\
\hline 41 & 10 & \begin{tabular}{|l|}
22 \\
\end{tabular} & LD & 17 & 0 & 0 & 0 & 0 & 0 & 0 & 0 & 0 & 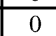 \\
\hline & 11 & \begin{tabular}{|l}
22 \\
\end{tabular} & LD & 550 & 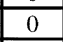 & 0 & 0 & 0 & 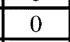 & 0 & 0 & 0 & 0 \\
\hline 43 & 14 & \begin{tabular}{|l|}
22 \\
\end{tabular} & LD & 190 & 0 & 0 & 0 & 0 & 0 & 0 & 0 & 0 & 0 \\
\hline 44 & 13 & \begin{tabular}{|l|}
22 \\
\end{tabular} & LD & 710 & 0 & 0 & 0 & 0 & 0 & 0 & 0 & 0 & 0 \\
\hline 45 & $\frac{15}{15}$ & \begin{tabular}{|l|}
22 \\
\end{tabular} & $\mathrm{LD}$ & 450 & 0 & 0 & 0 & 0 & 0 & 0 & 0 & 0 & 0 \\
\hline & 17 & \begin{tabular}{|l|}
22 \\
\end{tabular} & LD & 870 & 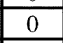 & 0 & 0 & 0 & 0 & 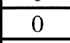 & 0 & 0 & 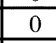 \\
\hline 47 & 7 & \begin{tabular}{|l|}
22 \\
\end{tabular} & $\mathrm{LD}$ & 290 & 0 & 0 & 0 & 0 & 0 & 0 & 0 & 0 & 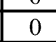 \\
\hline 48 & 5 & \begin{tabular}{|l|}
22 \\
\end{tabular} & LD & 70 & 0 & \begin{tabular}{|l|l} 
\\
\end{tabular} & 0 & 0 & 0 & 0 & 0 & 0 & 0 \\
\hline
\end{tabular}

TABLE II

ForCED OUTAGE RATES OF GENERATORS AND LINES

\begin{tabular}{c|c|c|c|c|c}
\hline NL & FOR & NL & FOR & NL & FOR \\
\hline 1 & 0.012 & 13 & 0.0012 & 25 & 0.0014 \\
\hline 2 & 0.015 & 14 & 0.0015 & 26 & 0.0020 \\
\hline 3 & 0.010 & 15 & 0.0015 & 27 & 0.0018 \\
\hline 4 & 0.015 & 16 & 0.0012 & 28 & 0.0022 \\
\hline 5 & 0.010 & 17 & 0.0015 & 29 & 0.0020 \\
\hline 6 & 0.012 & 18 & 0.0014 & 30 & 0.0025 \\
\hline 7 & 0.0125 & 19 & 0.0015 & 31 & 0.0012 \\
\hline 8 & 0.0155 & 20 & 0.0016 & 32 & 0.0015 \\
\hline 9 & 0.0015 & 21 & 0.0018 & 33 & 0.0011 \\
\hline 10 & 0.0020 & 22 & 0.0012 & 34 & 0.0011 \\
\hline 11 & 0.0015 & 23 & 0.0012 & 35 & 0.0021 \\
\hline 12 & 0.0012 & 24 & 0.0012 & 36 & 0.0022 \\
\hline & & & & &
\end{tabular}

The optimal expansion plans that resulted from changing the transmission system reliability criteria ${ }_{R} \mathrm{LOLE}_{\mathrm{TS}}$ are given in 


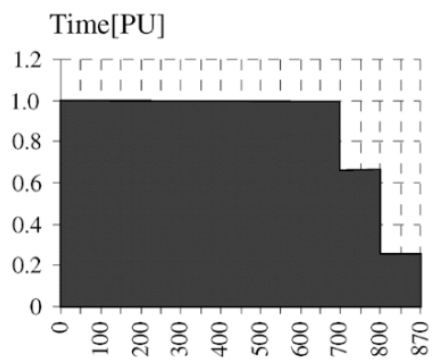
Load[MW]

(a)

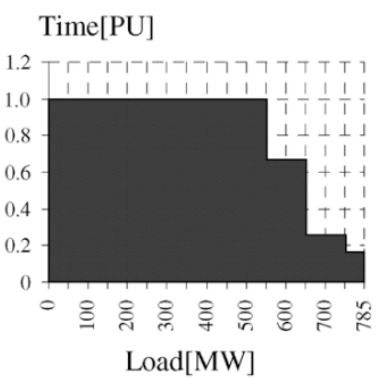

(a)

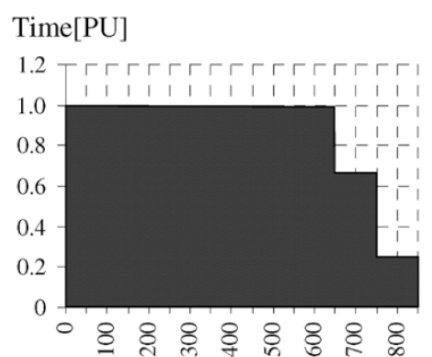

Load[MW]

(b)

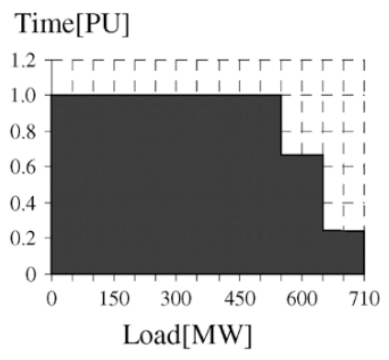

(b)

Fig. 4. Inverted load duration curves at the buses with the four largest loads. (Top) (a) ILDC at Bus 17. (b) ILDC at Bus 2. (Bottom) (a) ILDC at Bus 21. (b) ILDC at Bus 13.

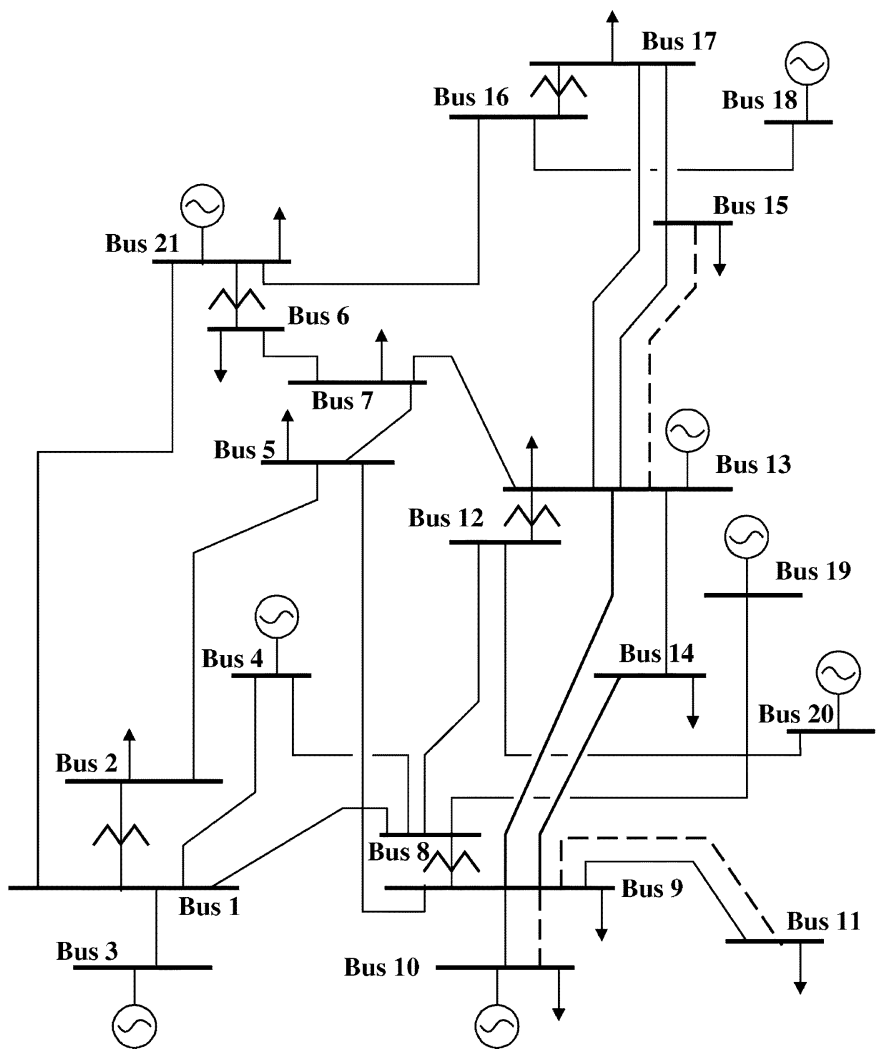

Fig. 5. Optimal system by the probabilistic approach $\left(_{R} \mathrm{LOLE}_{\mathrm{TS}}=50\right.$ [hrs/yr]).

Table IV. The tabulated results indicate that as the ${ }_{R} \mathrm{LOLE}_{\mathrm{TS}}$ increases, the total construction cost decreases, and reliability

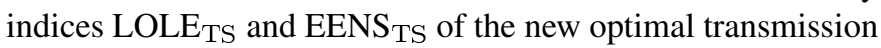
system increase.

In the second case study, the transmission system expansion plan using the bus/nodal reliability criteria ${ }_{R} \mathrm{LOLE}_{\mathrm{Bus}}$ instead

TABLE III

RELIABILITY INDICES AT THE LOAD BUSES IN THE CASE OF $\left({ }_{R} \mathrm{LOLE}_{\mathrm{TS}}=50[\mathrm{hrs} / \mathrm{yr}]\right)$

\begin{tabular}{c|c|c|c|c}
\hline $\begin{array}{c}\text { Load Bus } \\
\text { Number }\end{array}$ & $\begin{array}{c}L O L E_{\text {Bus }} \\
{[\mathrm{hrs} / \mathrm{yr}]}\end{array}$ & $\begin{array}{c}E E N S_{\text {Bus }} \\
{[\mathrm{MWh} / \mathrm{yr}]}\end{array}$ & $\begin{array}{c}E I R_{\text {Bus }} \\
{[\mathrm{PU}]}\end{array}$ & $\begin{array}{c}\text { Remark } \\
\left({ }_{R} L O L E_{T S}\right)\end{array}$ \\
\hline 21 & 45.22 & 8,486 & 0.998504 & \\
\hline 6 & 44.81 & 9,307 & 0.998344 & \\
\hline 2 & 55.77 & 12,073 & 0.998142 & Over \\
\hline 9 & 38.20 & 6,496 & 0.998534 & \\
\hline 10 & 0.0 & 0 & 1.000000 & \\
\hline 11 & 37.35 & 5,926 & 0.998468 & \\
\hline 14 & 14.25 & 1,016 & 0.999159 & \\
\hline 13 & 63.06 & 10,378 & 0.998118 & Over \\
\hline 15 & 45.52 & 4,968 & 0.998340 & \\
\hline 17 & 65.57 & 12,770 & 0.998134 & Over \\
\hline 7 & 16.73 & 1,564 & 0.999046 & \\
\hline 5 & 7.12 & 356 & 0.999299 & \\
\hline
\end{tabular}

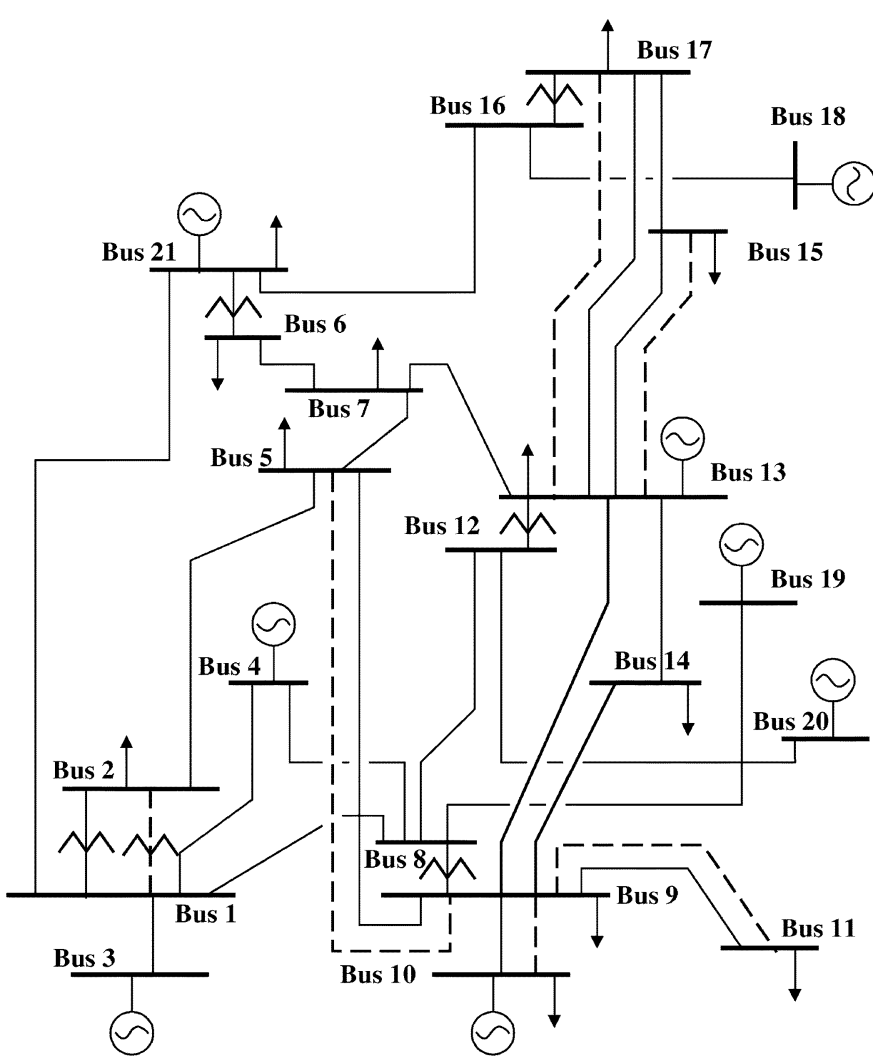

Fig. 6. Optimal system by the probabilistic approach ${ }_{{ }_{R}} \mathrm{LOLE}_{\mathrm{TS}}=25$ [hrs/yr]).

of the system reliability criteria ${ }_{R} \mathrm{LOLE}_{\mathrm{TS}}$ in (5) was simulated so that all bus reliability levels of the new system should satisfy this bus reliability criteria ${ }_{R} \mathrm{LOLE}_{\mathrm{Bus}}=50$ [hrs/yr].

The new optimal system in the second case is shown in Fig. 7. Table $\mathrm{V}$ shows the reliability indices at the load buses in the case of $R_{R} \mathrm{LOLE}_{\mathrm{Bus}}=50$ [hrs/yr]. A maximum LOLE $\mathrm{Bus}_{\text {in }}$ the new optimal system is the $\mathrm{LOLE}_{\mathrm{Bus}_{2}}=41.73[\mathrm{hrs} / \mathrm{yr}]$. This maximum value satisfies the required probabilistic bus reliability criterion ${ }_{R} \mathrm{LOLE}_{\mathrm{Bus}}=50[\mathrm{hrs} / \mathrm{yr}]$. The optimal solution has a construction cost of $348[\mathrm{M} \$]$ and the new construction elements of $\mathrm{TF}_{1-2}^{1}, \mathrm{~T}_{13-17}^{1}, \mathrm{~T}_{13-15}^{1}$, and $\mathrm{T}_{9-11}^{1}$. This second plan using bus/nodal reliability criteria suggests a stronger grid 
TABLE IV

Optimal Expansion Plans Due to Changing the System RELIABILITY CRITERION ${ }_{R}$ LOLE $_{\mathrm{TS}}$

\begin{tabular}{|c|c|c|c|c|c|}
\hline $\begin{array}{c}{ }_{R} L O L E_{T S} \\
{[\mathrm{hrs} / \mathrm{yr}]} \\
\end{array}$ & $\begin{array}{l}\text { Construction of } \\
\text { New Lines }\end{array}$ & $\begin{array}{l}\text { Cost }_{\mathrm{T}} \\
{[\mathrm{M} \$]}\end{array}$ & $\begin{array}{c}L O L E_{T S} \\
{[\mathrm{hrs} / \mathrm{yr}]}\end{array}$ & $\begin{array}{r}E E N S_{T S} \\
{[\mathrm{MWh} / \mathrm{yr}]}\end{array}$ & Remarks \\
\hline 25 & $\begin{array}{c}\mathrm{TF}_{1-2}{ }^{1}, \mathrm{~T}_{5-9}{ }^{1}, \\
\mathrm{~T}_{13-17}{ }^{1}, \mathrm{~T}_{13-15}{ }^{1} \\
\mathrm{~T}_{9-10}{ }^{1} \text {, and } \mathrm{T}_{9-11}{ }^{1}\end{array}$ & 511 & 24.42 & 29,942 & \\
\hline 30 & $\begin{array}{c}\mathrm{TF}_{1-2}{ }^{1}, \mathrm{~T}_{13-17}{ }^{1} \\
\mathrm{~T}_{13-15^{1}}, \mathrm{~T}_{9-10}{ }^{1} \\
\text { and } \mathrm{T}_{9-11}{ }^{1}\end{array}$ & 429 & 26.54 & 31,645 & \\
\hline 35 & $\begin{array}{c}\mathrm{TF}_{1-2}{ }^{1}, \mathrm{~T}_{13-17}{ }^{1}, \\
\mathrm{~T}_{13-15}{ }^{1} \text {, and } \\
\mathrm{T}_{9-11} \\
\end{array}$ & 348 & 31.64 & 39,841 & \\
\hline 40,45 & $\begin{array}{l}\mathrm{T}_{13-17}{ }^{1}, \mathrm{~T}_{13-15}{ }^{1}, \\
\mathrm{~T}_{9-10}{ }^{1} \text {, and } \mathrm{T}_{9-11}{ }^{1}\end{array}$ & 278 & 39.68 & 69,580 & \\
\hline 50,55 & $\begin{array}{c}\mathrm{T}_{13-15^{1}}{ }, \mathrm{~T}_{9-10}{ }^{1}, \\
\text { and } \mathrm{T}_{9-11}{ }^{1}\end{array}$ & 209 & 45.47 & 73,339 & $\begin{array}{c}\text { SAME } \\
\text { WITH } \\
\text { BRR }=0 \%\end{array}$ \\
\hline $60,65,70$ & $\begin{array}{c}\mathrm{T}_{21-1}{ }^{1}, \mathrm{~T}_{13-15^{1}}{ }^{1}, \\
\text { and } \mathrm{T}_{9-11}{ }^{1}\end{array}$ & 157 & 55.10 & 83,654 & \\
\hline $75, \ldots, 100$ & $\begin{array}{l}\mathrm{T}_{21-1}{ }^{1}, \mathrm{~T}_{9-11}{ }^{1} \text {, } \\
\text { and } \mathrm{T}_{15-17}{ }^{1}\end{array}$ & 154 & 73.52 & 105,454 & \\
\hline
\end{tabular}

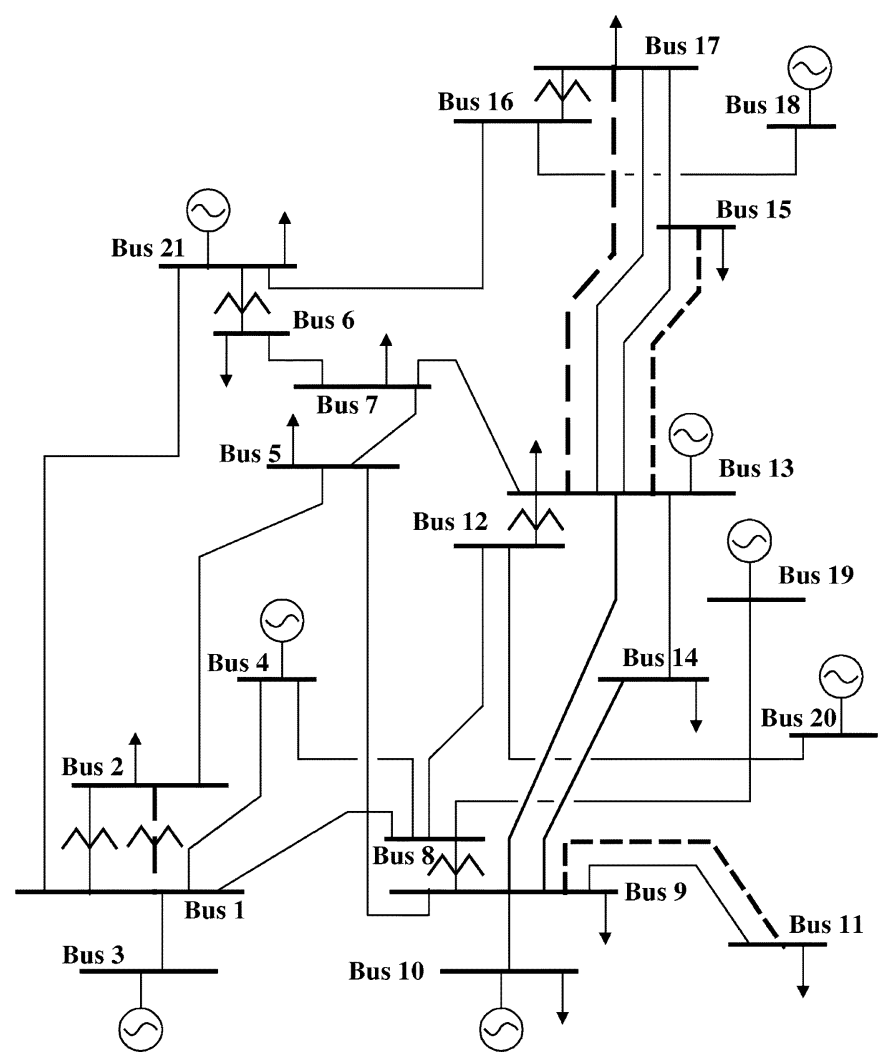

Fig. 7. Optimal system by the probabilistic approach $\left({ }_{R} \mathrm{LOLE}_{\mathrm{Bus}}=50\right.$ [hrs/yr]).

system than the first case optimal plan using the system reliability criteria. The second plan has a construction cost of $139[\mathrm{M} \$]$ more than that of the former plan. The additional transmission elements are required in order to decrease the LOLE indices of buses 2,13 , and 17 , which have reliability levels in excess of the approved bus reliability criterion.

The optimal expansion plans that resulted from changing bus reliability criteria ${ }_{R} \mathrm{LOLE}_{\mathrm{Bus}}$ are given in Table VI. The tabulated results indicate that as the ${ }_{R} \mathrm{LOLE}_{\mathrm{Bus}}$ increases, the total
TABLE V

RELIABILITY INDICES AT THE LOAD BUSES IN THE CASE OF ${ }_{R}$ LOLE $_{\text {Bus }}=50[\mathrm{hrs} / \mathrm{yr}]$

\begin{tabular}{c|c|c|c|c}
\hline $\begin{array}{c}\text { Load Bus } \\
\text { Number }\end{array}$ & $\begin{array}{c}L O L E_{\text {Bus }} \\
{[\mathrm{hrs} / \mathrm{yr}]}\end{array}$ & $\begin{array}{c}E E N S_{\text {Bus }} \\
{[\mathrm{MWh} / \mathrm{yr}]}\end{array}$ & $\begin{array}{c}E I R_{\text {Bus }} \\
{[\mathrm{PU}]}\end{array}$ & $\begin{array}{c}\text { Remark } \\
\left(\text { LOLE }_{\text {Bus }}\right)\end{array}$ \\
\hline 21 & 31.45 & 4,375 & 0.999229 & \\
\hline 6 & 39.08 & 5,517 & 0.999019 & \\
\hline 2 & $\underline{\mathbf{4 1 . 7 3}}$ & 6,784 & 0.998956 & maximum \\
\hline 9 & 30.76 & 3,534 & 0.999203 & \\
\hline 10 & 0.00 & 0 & 1.000000 & \\
\hline 11 & 29.82 & 3,257 & 0.999158 & \\
\hline 14 & 9.75 & 492 & 0.999593 & \\
\hline 13 & 39.36 & 5,653 & 0.998975 & Satisfied \\
\hline 15 & 27.64 & 2,429 & 0.999188 & \\
\hline 17 & 36.57 & 7,050 & 0.998970 & Satisfied \\
\hline 7 & 10.45 & 626 & 0.999618 & \\
\hline 5 & 2.50 & 125 & 0.999754 & \\
\hline
\end{tabular}

TABLE VI

Optimal Expansion Plans Due to Changing the Bus RELIABILITY CRITERION ${ }_{R}$ LOLE $_{\text {Bus }}$

\begin{tabular}{|c|c|c|c|c|c|}
\hline $\begin{array}{c}{ }_{R}{ }^{L O L E_{B u s}} \\
{[\mathrm{hrs} / \mathrm{yr}]}\end{array}$ & $\begin{array}{l}\text { Construction of } \\
\text { New Lines }\end{array}$ & $\begin{array}{l}\text { Cost }_{\mathrm{T}} \\
{[\mathrm{M} \$]}\end{array}$ & $\begin{array}{l}L O L E_{T S} \\
{[\mathrm{hrs} / \mathrm{yr}]}\end{array}$ & $\begin{array}{r}E E N S_{T S} \\
{[\mathrm{MWh} / \mathrm{yr}]}\end{array}$ & Remarks \\
\hline 35 & $\begin{array}{c}\mathrm{TF}_{1-2}{ }^{1}, \mathrm{~T}_{5-9}{ }^{1}, \\
\mathrm{~T}_{13-17}, \mathrm{~T}_{13-15}{ }^{1}, \\
\mathrm{~T}_{9-10}{ }^{1} \text {, and } \mathrm{T}_{9-11}{ }^{1}\end{array}$ & 511 & 24.42 & 29,942 & \\
\hline 40 & $\begin{array}{c}\mathrm{TF}_{1-2}{ }^{1}, \mathrm{~T}_{13-17}{ }^{1}, \\
\mathrm{~T}_{13-15}{ }^{1}, \mathrm{~T}_{9-10^{1}}, \\
\text { and } \mathrm{T}_{9-11}{ }^{1}\end{array}$ & 429 & 26.54 & 31,645 & \\
\hline 45,50 & $\begin{array}{c}\mathrm{TF}_{1-2}{ }^{1}, \mathrm{~T}_{13-17}{ }^{1}, \\
\mathrm{~T}_{13-15}{ }^{1} \text {, and } \\
\mathrm{T}_{9-11}{ }^{1}\end{array}$ & 348 & 31.64 & 39,841 & \\
\hline $55,60,65$ & $\begin{array}{l}\mathrm{T}_{13-17}{ }^{1}, \mathrm{~T}_{13-15}{ }^{1}, \\
\mathrm{~T}_{9-10}{ }^{1}, \text { and } \mathrm{T}_{9-11}{ }^{1}\end{array}$ & 278 & 39.68 & 69,580 & \\
\hline 70 & $\begin{array}{c}\mathrm{T}_{13-15^{1}}, \mathrm{~T}_{9-10^{1}}{ }^{1} \\
\text { and } \mathrm{T}_{9-11}{ }^{1}\end{array}$ & 209 & 45.47 & 73,339 & $\begin{array}{c}\text { SAME } \\
\text { WITH } \\
\text { BRR }=0 \%\end{array}$ \\
\hline $75, \ldots, 100$ & $\begin{array}{c}\mathrm{T}_{21-1}{ }^{1}, \mathrm{~T}_{13-15}{ }^{1}, \\
\text { and } \mathrm{T}_{9-11} 1\end{array}$ & 157 & 55.10 & 83,654 & \\
\hline
\end{tabular}

construction cost decreases, and reliability indices LOLE $\mathrm{TS}_{\mathrm{TS}}$ and EENS $_{\mathrm{TS}}$ of the new optimal transmission system increase.

The third case study has a market characteristic that the grid owner has to construct the new grid to supply electrical energy with the bus reliability level ${ }_{R} \mathrm{LOLE}_{\mathrm{Bus} 17}=50[\mathrm{hrs} / \mathrm{yr}]$ for the customers of bus 17 [This load point is the third largest city (Daegu) in Korea] and with a system reliability level ${ }_{R} \mathrm{LOLE}_{\mathrm{TS}}=50[\mathrm{hrs} / \mathrm{yr}]$ for the other customers.

Fig. 8 shows the new optimal system produced in this case study. The optimal solution has the construction cost of 278[M $\$$ ] and the new construction elements of $\mathrm{T}_{13-17}^{1}, \mathrm{~T}_{13-15}^{1}, \mathrm{~T}_{9-10}^{1}$, and $\mathrm{T}_{9-11}^{1}$. Table VII shows the bus reliability indices of the optimal plan. The system reliability level LOLE $\mathrm{TS}_{\mathrm{T}}$ and the bus 17 reliability level of the optimal system are 39.68 [hrs/yr] and 49.49 [hrs/yr], respectively. These levels satisfy the two required probabilistic reliability criteria ${ }_{R} \mathrm{LOLE}_{\mathrm{TS}}=50[\mathrm{hrs} / \mathrm{yr}]$ for the system reliability criterion and ${ }_{R} \mathrm{LOLE}_{B u s 17}=50[\mathrm{hrs} / \mathrm{yr}]$ for the bus reliability criterion at the bus 17 . The new third plan using the specified bus and system reliability criteria creates a stronger grid system with higher cost than the first case plan using the system reliability criterion only. It is interesting to note 


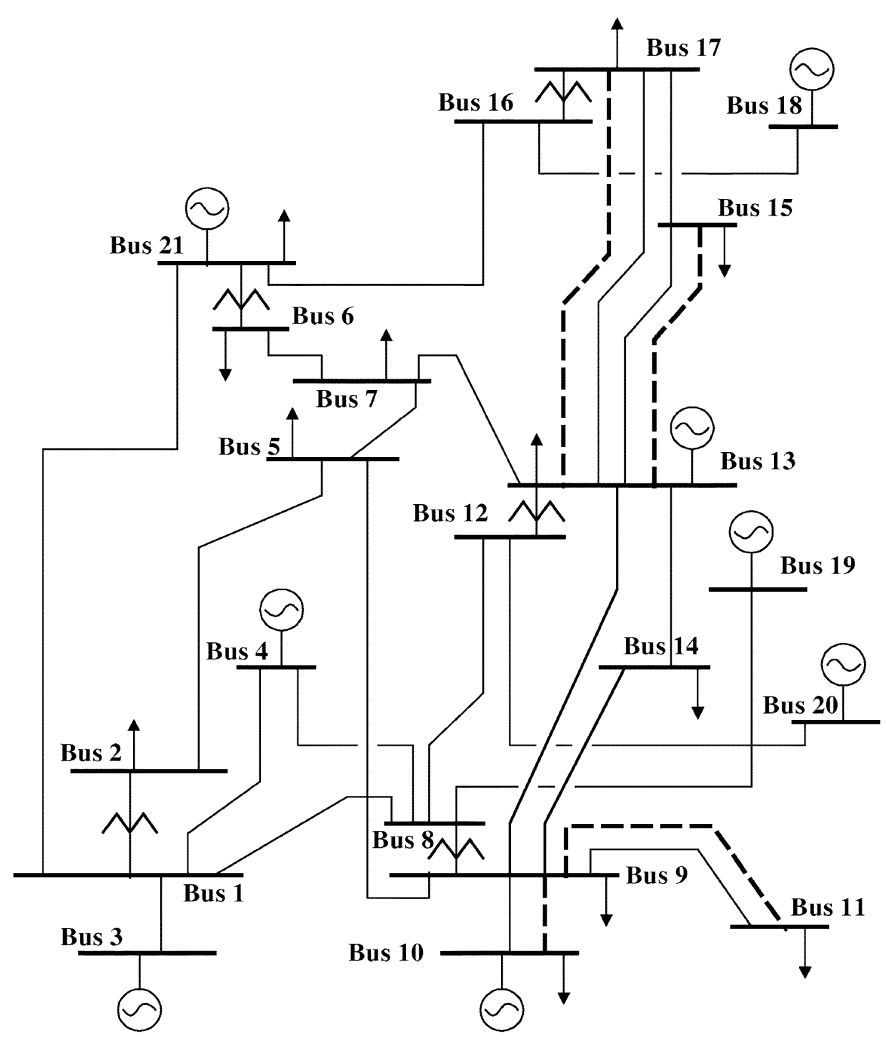

Fig. 8. Optimal system by the probabilistic approach ${ }_{R}{ }_{R}$ LOLE $E_{\mathrm{TS}}=50$ $[\mathrm{hrs} / \mathrm{yr}]$ and $\left.{ }_{R} \mathrm{LOLE}_{\mathrm{Bus} 17}=50[\mathrm{hrs} / \mathrm{yr}]\right)$.

TABLE VII

RELIABILITY INDICES AT THE LOAD BUSES IN THE CASE OF TWO CONSTRAINTS ${ }_{R}$ LOLE $_{\mathrm{TS}}=50[\mathrm{hrs} / \mathrm{yr}]$ and ${ }_{R}$ LOLE $_{\mathrm{Bus} 17}=50[\mathrm{hrs} / \mathrm{yr}]$

\begin{tabular}{c|c|c|c|c}
\hline $\begin{array}{c}\text { Load Bus } \\
\text { Number }\end{array}$ & $\begin{array}{c}L O L E_{\text {Bus }} \\
{[\mathrm{hrs} / \mathrm{yr}]}\end{array}$ & $\begin{array}{c}E E N S_{\text {Bus }} \\
{[\mathrm{MWh} / \mathrm{yr}]}\end{array}$ & $\begin{array}{c}E I R_{\text {Bus }} \\
{[\mathrm{PU}]}\end{array}$ & $\begin{array}{c}\text { Remark } \\
\left({ }_{R} L O L E_{T S}\right)\end{array}$ \\
\hline 21 & 38.19 & 8,094 & 0.998574 & \\
\hline 6 & 44.78 & 9,308 & 0.998344 & \\
\hline 2 & 50.08 & 11,220 & 0.998273 & \\
\hline 9 & 34.52 & 6,496 & 0.998578 & \\
\hline 10 & 0.0 & 0 & 1.000000 & \\
\hline 11 & 37.28 & 5,918 & 0.998470 & \\
\hline 14 & 14.22 & 1,015 & 0.999161 & \\
\hline 13 & 49.26 & 9,523 & 0.998274 & \\
\hline 15 & 36.92 & 4,523 & 0.998489 & \\
\hline 17 & $\underline{49.49}$ & 11,755 & 0.998282 & Satisfied \\
\hline 7 & 16.73 & 1,564 & 0.999046 & \\
\hline 5 & 7.11 & 356 & 0.999300 & \\
\hline & & & &
\end{tabular}

that the optimal plan involves a new line between buses 17 and 13 in order to satisfy the bus 17 reliability criterion.

The optimal expansion plans resulting from changing the bus 17 reliability criterion ${ }_{R}$ LOLE $_{\text {BUS17 }}$ are given in Table VIII. The tabulated results indicate that as the ${ }_{R} \mathrm{LOLE}_{\mathrm{BUS} 17}$ increases, the total construction cost decreases, and the actual reliability indices, the specified $\mathrm{LOLE}_{\mathrm{BUS} 17}$, as well as $\mathrm{LOLE}_{\mathrm{TS}}$ and $\mathrm{EENS}_{\mathrm{TS}}$ of the new optimal transmission system increase. The same new plans are obtained for ${ }_{R} \mathrm{LOLE}_{\mathrm{Bus} 17}=50$ [hrs/yr] and over. This comes from the fact that the system reliability constraint is more dominant than the bus reliability
TABLE VIII

OPTIMAL EXPANSION PLANS DUE TO CHANGING THE RELIABILITY CRITERION ${ }_{R}$ LOLE $_{\text {Bus } \# 17}$ AND FIXING ${ }_{R}$ LOLE $_{\text {TS }}=50[\mathrm{hrs} / \mathrm{yr}]$

\begin{tabular}{|c|c|c|c|c|c|}
\hline $\begin{array}{c}{ }_{R}{ }_{2} O L E_{\text {BUSHIt }} \\
{[\mathrm{hrs} / \mathrm{yr}]}\end{array}$ & $\begin{array}{l}\text { Construction of } \\
\text { New Lines }\end{array}$ & $\begin{array}{l}\text { Cost }_{\mathrm{T}} \\
{[\mathrm{M} \$]}\end{array}$ & 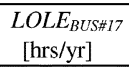 & $\begin{array}{c}L_{0 L E_{T S}} \\
{[\mathrm{hrs} / \mathrm{yr}]}\end{array}$ & $\begin{array}{c}E E N S_{T S} \\
{[\mathrm{MWh} / \mathrm{yr}]}\end{array}$ \\
\hline 35 & $\begin{array}{c}\mathrm{TF}_{1-2}{ }^{1}, \mathrm{~T}_{13-17}{ }^{1} \\
\mathrm{~T}_{13-15}{ }^{1}, \mathrm{~T}_{9-10} 1 \\
\text { and } \mathrm{T}_{9-11}{ }^{1}\end{array}$ & 429 & 32.99 & 26.54 & 31,645 \\
\hline 40,45 & $\begin{array}{l}\mathrm{TF}_{1-2}{ }^{1}, \mathrm{~T}_{13-17^{1}}, \\
\mathrm{~T}_{13-15^{1}}{ }^{2} \text { and } 9-11\end{array}$ & 348 & 36.57 & 31.64 & 39,841 \\
\hline $\begin{array}{l}50,55,60 \\
\text { and } 65\end{array}$ & $\begin{array}{l}\mathrm{T}_{13-17}^{1}, \mathrm{~T}_{13-15}{ }^{1}, \\
\mathrm{~T}_{9-10}{ }^{1} \text {, and } \mathrm{T}_{9-11}{ }^{1}\end{array}$ & 278 & 49.49 & 39.68 & 69,580 \\
\hline
\end{tabular}

constraint and the determination of the optimal plan is dependent on the system reliability constraint rather than bus reliability constraint in the cases of $50[\mathrm{hrs} / \mathrm{yr}]$ and over.

In summary, Figs. 5-8 in three cases show that very different expansion plans can result by using different types and magnitudes for the probabilistic reliability criterion. The case studies suggest that bus/nodal probabilistic reliability criteria result in a stronger grid than that produced using system reliability criteria.

\section{CONCLUSION}

This paper addresses transmission system expansion planning using a probabilistic reliability criterion. The proposed procedure is a first step in preparing a transmission system expansion plan employing probabilistic reliability assessment methods to ensure the reliability of the electric power grid. Optimal locations and capacities of transmission lines can be determined using the proposed method. The paper presents a new and practical approach that should serve as a useful guide for the decision maker in selecting a reasonable expansion plan prior to checking system stability and dynamics in detail. The proposed method finds the optimal transmission system expansion plan considering uncertainties associated with the forced outage rates of the grid elements (transformers and lines). It models the problem as a probabilistic integer programming one and considers problem uncertainties through probabilistic modeling. A probabilistic branch and bound algorithm, which includes the network flow method, and the maximum flow-minimum cut set theorem is used to solve the problem. The case studies show that quite different planning alternatives can be determined from the use of the deterministic and probabilistic reliability approaches and different reliability criteria. The case studies on the 21-bus test system suggest that bus/nodal probabilistic reliability criteria result in a stronger grid than a grid produced using system reliability criteria. The paper shows that the proposed method can be used to perform transmission system expansion planning considering different individual bus reliability criteria. The proposed approach can, therefore, accommodate customers' requirements in a competitive electricity market environment.

\section{ACKNOWLEDGMENT}

This study was done by the Electrical Power Reliability/Power Quality Research Center, Korea, and PSERC, Cornell University, Ithaca, NY. 


\section{REFERENCES}

[1] J. A. Casazza and G. C. Loehr, The Evolution of Electric Power Transmission Under Deregulation. Piscataway, NJ: Educational Activities Board of IEEE, 2000.

[2] R. Fang and D. J. Hill, "A new strategy for transmission expansion in competitive electricity markets," IEEE, Trans. Power Syst., vol. 18, no. 1, pp. 374-380, Feb. 2003.

[3] M. Ilic et al., Power Systems Restructuring; Engineering and Economics. Norwell, MA: Kluwer Academic, 1998.

[4] M. Ilic, "Underlying paradigms for reliability under open access," in Proc. MIT Energy Lab. ISO Workshop Tutorial Course Notebook PowerCon, Perth, Australia, Dec. 2000.

[5] W. S. Read, W. K. Newman, I. J. Perez-Arriaga, H. Rudnick, M. R. Gent, and A. J. Roman, "Reliability in the new market structure (part 1)," IEEE Power Eng. Rev., vol. 19, no. 12, pp. 4-5, Dec. 1999.

[6] - "Reliability in the new market structure (part 2)," IEEE Power Eng. Rev., vol. 20, no. 1, pp. 10-16, Jan. 2000.

[7] X. Wang and J. R. McDonald, Modern Power System Planning. New York: McGraw-Hill, 1994.

[8] S. T. Y. Lee, K. L. Hocks, and E. Hnyilicza, "Transmission expansion of branch and bound integer programming with optimal cost capacity curves," IEEE Trans. Power App. Syst., vol. PAS-93, no. 5, pp. 1390-1400, Aug. 1970.

[9] J. Contreras and F. Wu, "A Kernel-oriented algorithm for transmission expansion planning," IEEE Trans. Power Syst., vol. 15, no. 4, pp. 1434-1440, Nov. 2000.

[10] M. V. F. Pereira and L. M. V. G. Pinto, "Application of sensitivity analysis of load supplying capacity to interactive transmission expansion planning," IEEE Trans. Power App. Syst., vol. PAS-104, pp. 381-389, Feb. 1985.

[11] R. Romero and A. Monticelli, "A hierarchical decomposition approach for transmission network expansion planning," IEEE Trans. Power Syst., vol. 9, no. 1, pp. 373-380, Feb. 1994.

[12] _ - "A zero-one implicit enumeration method for optimizing investments in transmission expansion planning," IEEE Trans. Power Syst., vol. 9, no. 3, pp. 1385-1391, Aug. 1994.

[13] S. Binato, M. V. Pereira, and S. Granville, "A new benders decomposition approach to solve power transmission network design problems," IEEE Trans. Power Syst., vol. 16, no. 2, pp. 235-240, May 2001.

[14] R. Romero, R. A. Gallego, and A. Monticelli, "Transmission system expansion planning by simulated annealing," IEEE Trans. Power Syst., vol. 11, no. 1, pp. 364-369, Feb. 1996.

[15] E. L. Silva, H. A. Gil, and J. M. Areiza, "Transmission network expansion planning under an improved genetic algorithm," IEEE Trans. Power Syst., vol. 15, no. 3, pp. 1168-1175, Aug. 2000.

[16] R. A. Gallego, R. Romero, and A. J. Monticelli, "Tabu search algorithm for network synthesis," IEEE Trans. Power Syst., vol. 15, no. 2, pp. 490-495, May 2000.

[17] L. Bahiense, G. C. Oliveira, M. Pereira, and S. Granville, "A mixed integer disjunctive model for transmission network expansion," IEEE Trans. Power Syst., vol. 16, no. 3, pp. 560-565, Aug. 2001.

[18] P. Zhang, S. T. Lee, and D. Sobajic, "Moving toward probabilistic reliability assessment methods," in Proc. 8th Int. Conf. Probabilistic Methods Appl. Power Syst., Ames, IA, Sept. 12-16, 2004.

[19] K. Audomvongseree and A. Yokoyama, "Consideration of an appropriate TTC by probabilistic approach," IEEE Trans. Power Syst., vol. 19, no. 1, pp. 375-383, Feb. 2004.

[20] H. J. Zimmermann, Fuzzy Set Theory and Its Applications. Norwell, MA: Kluwer, 1986.

[21] J. P. Ignizio and S. C. Daniels, "Fuzzy multi-criteria integer programming via fuzzy generalized networks," Fuzzy Sets Syst., vol. 10, pp. 261-270, 1975.

[22] R. Billinton and E. Khan, "A security based approach to composite power system reliability evaluation," IEEE Trans. Power Syst., vol. PS-7, no. 1, pp. 65-72, Feb. 1992.

[23] R. Billinton and W. Zhang, "Enhanced adequacy equivalent for composite power system reliability evaluation," in Proc. Inst. Elect. Eng., Gener., Transm., Distrib., vol. 143, Sep. 1996, pp. 420-426.

[24] B. E. Gillett, Introduction to Operations Research: A Computer-Oriented Algorithmic Approach. New York: McGraw-Hill, 1976.

[25] K. Takahashi, Power Systems Engineering. Tokyo, Japan: Corona, 1977. (in Japanese).

[26] T. Okada and Y. Kawai, "Expansion planning of power systems with stepwise cost characteristics," J. Inst. Elect. Eng. Japan, vol. 90, no. 8, pp. 166-174, Aug. 1970. (in Japanese).
[27] L. R. Ford and D. R. Fulkerson, Flow in Network. Princeton, NJ: Princeton Univ. Press, 1974, pp. 93-172.

[28] R. Billinton and R. N. Allan, Reliability Evaluation of Power Systems. New York: Plenum Press, 1996.

[29] J. Choi, D. Do, S. Moon, and R. Billinton, "Development of a method for ELDC construction in a composite power system," in Proc. LESCOPE, Halifax, NS, Canada, Jun. 1999.

[30] J. Choi, H. Kim, J. Cha, and R. Billinton, "Nodal probabilistic congestion and reliability evaluation of a transmission system under deregulated electricity market," in Proc. IEEE Power Eng. Soc. Summer Meeting, Vancouver, BC, Canada, Jul. 16-19, 2001.

[31] J. Choi, R. Billinton, and M. Futuhi-Firuzabed, "Development of a new nodal effective load model considering of transmission system element unavailabilities," Proc. Inst. Elect. Eng., Transm. Distrib., to be published.

[32] S. Kang, T. Tran, J. Choi, J. Cha, D. Rho, and R. Billinton, "The best line choice for transmission system expansion planning on the side of the highest reliability level," Korean Inst. Elect. Eng., Int. Trans. Power Eng., vol. 4-A, no. 2, pp. 84-90, Jun. 2004.

[33] J. Choi, A. A. El-Keib, and T. Tran, "A fuzzy branch and bound-based transmission system expansion planning for the highest satisfaction level of the decision maker," IEEE Trans. Power Syst., vol. 20, no. 1, pp. 476-484, Feb. 2005.

[34] J. S. Choi, T. T. Tran, S. R. Kang, D. H. Jeon, C. H. Lee, and R. Billinton, "A study on optimal reliability criterion determination for transmission system expansion planning," in Proc. IEEE Power Eng. Soc. Gen. Meeting, Denver, CO, Jun. 6-10, 2004.

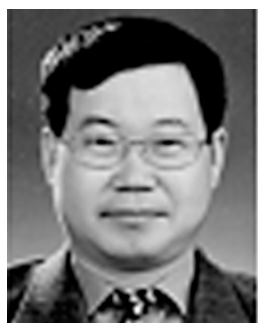

Jaeseok Choi (S'88-M'91-SM'05) was born in Kyeongju, Korea, in 1958. He received B.Sc., M.Sc., and Ph.D. degrees from Korea University, Seoul, in 1981, 1984, and 1990, respectively.

His research interests include fuzzy applications, probabilistic production cost simulation, reliability evaluation, and outage cost assessment of power systems. He was a Postdoctoral Fellow at University of Saskatchewan, Saskatoon, SK, Canada, on 1996. Since 1991, he has been on the faculty of Gyeongsang National University, Jinju, Korea, where he is now a Professor. Currently, he is a Visiting Professor at Cornell University, Ithaca, NY.

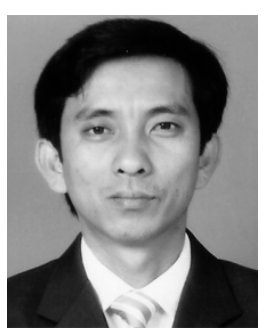

Trungtinh Tran was born in Mochoa, Vietnam, in 1973. He received B.Sc. and M.Sc. degrees from Cantho University, Cantho, Vietnam, and Gyeongsang National University, Jinju, Korea, in 1997 and 2004, respectively. He is now working toward the Ph.D. degree at Gyeongsang National University.

His research interests include transmission expansion planning using fuzzy set theory and reliability evaluation of power systems.

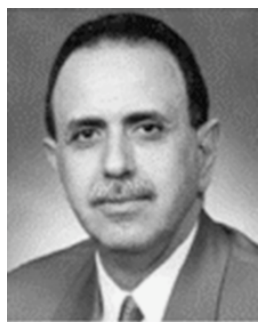

A. (Rahim) A. El-Keib (SM'89) received the B.Sc.(Hons.) degree in 1973 from the University of Tripoli, Tripoli, Libya, the M.S. degree in 1976 from the University of Southern California, Los Angeles, and the Ph.D. degree in 1984 from North Carolina State University (NCSU), Raleigh, all in electrical engineering.

He has taught at the University of Tripoli, NCSU, and The University of Alabama, Tuscaloosa, where he is a Professor. His research interests include planning, operation and control of power system, application of artificial intelligence in power systems, and distribution system automation.

Dr. El-Keib is a member of several IEEE/PES committees, subcommittees, and task forces. 


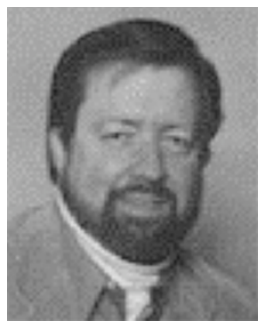

Robert Thomas (S'66-M'73-SM'82-F'88) was born in Detroit, Michigan, in 1942.

$\mathrm{He}$ is a Professor in the Department of Electrical and Computer Engineering, Cornell University, Ithaca, NY. His technical background is broadly in the areas of systems analysis and control of large-scale electric power systems. He has published in the areas of transient control and voltage collapse problems as well as technical, economic, and institutional impacts of restructuring.

Mr. Thomas is the founding Director of PSerc and CERTS. He was on assignment to the USDOE in 2003 as a Senior Advisor to the Director of the Office of Electric Transmission and Distribution. He is a member of Tau Beta Pi, Eta Kappa Nu, Sigma Xi, and ASEE.

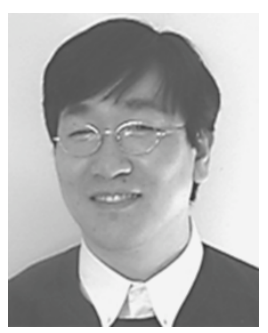

HyungSeon Oh received the M.S. degree in materials science and engineering in 2002 and is currently working toward the Ph.D. degree in electrical and computer engineering at Cornell University, Ithaca, NY.

His research interests include electricity trading, computer modeling, and simulation.

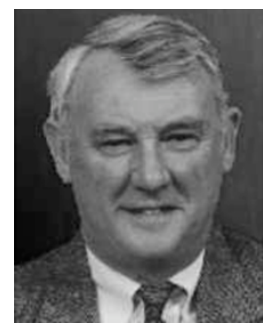

Roy Billinton (S'59-M'64-SM'73-F'78) came to Canada from England in 1952. He received the B.Sc. and M.Sc. degrees from the University of Manitoba, Winnipeg, MB, Canada, and Ph.D. and D.Sc. degrees from the University of Saskatchewan, Saskatoon, SK, Canada.

He worked for Manitoba Hydro in the System Planning and Production Divisions. He joined the University of Saskatchewan in 1964 and was formerly the Head of the Electrical Engineering Department. He presently is the C. J. Mackenzie Professor of Engineering and Acting Dean, Graduate Studies, Research and Extension of the College of Engineering. He is the author of papers on power system analysis, stability, economic system operation, and reliability and the author or coauthor of eight books on reliability.

Dr. Billinton is a Fellow of the EIC and the Royal Society of Canada and a Professional Engineer in the Province of Saskatchewan. 